\section{The effects of reward structure and partner's cooperation upon strategy}

\author{
LINDA ZENER SOLOMON, Baruch College \\ and \\ HARRY KAUFMANN, Hunter College \\ City University of New York, New York, N.Y.
}

Ss played a modified prisoner's dilemma game under one of four incentive conditions with either a cooperative or a competitive partner. In one population sample, when Ss were playing for points, a money (rather than points) reward for partners elicited significantly more cooperation. In a second population sample, Ss reciprocated their partners' strategy only when the Ss were playing for money rather than points. The possible effect of socioeconomic differences is discussed.

The present study was designed to test the implications of research on reward and cooperation in game situations. Gallo (1966), using a Deutsch \& Krauss (1960) trucking game, found that dyads playing for money were more cooperative than dyads playing for imaginary points. McClintock \& McNeel (1966), using a modified prisoner's dilemma game (MDG), found that Ss playing for a large money reward were more cooperative than Ss playing for a small money reward.

This reward or incentive-cooperation relationship could be attributed to one of two factors: social responsibility or economic gain. In the case of the former, Berkowitz and his colleagues (e.g., Berkowitz \& Daniels, 1963) have demonstrated that, in our society, there is a norm prescribing help for a dependent person. The presence and size of a money reward might be considered to indicate dependence, and the greater this dependence, the more the partners might feel obligated to help one another. With regard to economic gain, Gouldner (1960) has discussed the principle of reciprocity, i.e., the expectation that people "give as good as they get." In accordance with this social rule, the players might cooperate in order to induce the other player to cooperate as well. The importance of cooperation from the other person would increase as the potential reward increased, since, in dilemma-type games, when one person competes, the other person cannot win either money or points and, in the MDG, mutual cooperation is the most lucrative strategy.

The present study consisted of two separate but essentially similar experiments. Four reward or incentive groups were used in each experiment: $\mathrm{S}$ and partner were both playing for money; both were playing for points; or one person was playing for money and the other for points. It was predicted that, if primarily concerned with their responsibility to their partners, Ss would be more cooperative when their partners were playing for money than when their partners were playing for points (regardless of their own reward concerned with the implications of their partners' strategy for their own economic gain, Ss would be more cooperative when they themselves were playing for money (regardless of their partners' reward potential).

The type of matrix used for this study was the same as that used by McClintock \& McNeel (1966), although the incentive for mutual cooperation was increased in order to emphasize the importance of the reward. Unlike the McClintock and McNeel study, the partners were simulated (although the Ss were unaware of this) and, for the convenience of the two schools involved, the present experiments were conducted in groups, not pairs, and a smaller number of trials was given.

The procedure was designed so that the incentive manipulation might affect strategy despite the small number of trials. To facilitate prompt understanding of the game, Ss were given a list of all possible response-outcome pairs rather than the usual matrix. Moreover, the possible monetary reward per trial (10c) was close to that of the "large reward" group of McClintock and McNeel (12c) and appeared to be an exciting incentive to the young teenage Ss.

\section{METHOD}

\section{Experiment 1}

The Ss were 112 Grade 9 students at an Etobicoke, Ont, high school. The Ss played five trials of a version of the MDG (Fig. 1) and completed several questionnaires.

The experiment was conducted in four separate classrooms, each classroom being assigned to one of the four incentive conditions: potential). Conversely, if primarily
(1) S-money, partner-money $(\mathrm{S}-\$ / \mathrm{P}-\$) ;(2) \mathrm{S}-\mathrm{m}$ oney, partner-points (S-\$/P-\#); (3) S-points, partner-money $(\mathrm{S}-\# / \mathrm{P}-\mathrm{S}) ;(4) \mathrm{S}-\mathrm{p}$ oint $\mathrm{s}$, partner-points (S-\#/P-\#). Money reward was said to be $1 \mathrm{c}$ per point, and each group was told that their partners were in an adjoining room, with matching to be carried out by seat numbers.

On each trial, the Ss played the game by choosing either $X$ (cooperation) or $\mathrm{Y}$ (competition). After this choice had been made by all of the Ss, E collected the papers and "delivered" them to the "partners" in the "next room." She then returned and handed out the "partners' choices" to the Ss. The Ss in each group were assigned alternately to a cooperative (playing $X$ on all trials) or a competitive (playing $\mathrm{Y}$ on all trials) partner.

After the game, a questionnaire was completed. The Ss were then given $50 \mathrm{c}$ each and asked not to discuss the proceedings with their fellow students. Experiment 2

The Ss were 88 Grade 9 students at another Etobicoke high school. The surrounding neighborhood was of a higher socioeconomic level than that of the school of Experiment 1, a factor initially thought to be irrelevant to the study.

The procedure was identical to that of Experiment 1. RESULTS

Cooperative Behavior

For Trial 1, the number of cooperative choices (X) was summed for each incentive group and a 4 by 2 chi square carried out. For Trials 2-5, each $S$ was given a cooperation score based on the total number of Xs he or she chose on the four trials and a 4 by 2 analysis of variance (Incentive Group by. Partner's Strategy) was carried out. (Mean responses are shown in Table 1.)

There were no significant differences between groups in the number of Ss rendering cooperation on Trial 1. Analysis of variance of Trials 2-5 combined yielded a significant main effect of incentive group $(F=4.63, p<.01, d f=3 / 104)$; a Newman-Keuls test indicated that each of the three other groups was

\begin{tabular}{ccccc}
\multicolumn{2}{c}{ The Moves } & & \multicolumn{2}{c}{ Points Won by } \\
\cline { 5 - 5 } You & Other & & You & Other \\
\hline X & X & 10 & 10 \\
X & Y & 0 & 5 \\
Y & X & 5 & 0 \\
Y & Y & 0 & 0 \\
\hline
\end{tabular}

Fig. 1. The game matrix. 
Table 1

Means and Standard Deviations of Cooperation on Trials 2 to 5

\begin{tabular}{|c|c|c|c|c|}
\hline \multirow{3}{*}{$\begin{array}{c}\text { Incentive } \\
\text { Group }\end{array}$} & \multicolumn{2}{|c|}{ Experiment 1} & \multicolumn{2}{|c|}{ Experiment 2} \\
\hline & \multicolumn{2}{|c|}{ Partner } & \multicolumn{2}{|c|}{ Partner } \\
\hline & Cooperative & Competitive & Cooperative & Competitive \\
\hline $\mathbf{S}-\ddot{\div} / \mathbf{P}-\$$ & $\begin{array}{c}2.64 \\
(1.15)\end{array}$ & $\begin{array}{c}2.07 \\
(1.07)\end{array}$ & $\begin{array}{c}2.09 \\
(1.22)\end{array}$ & $\begin{array}{c}2.27 \\
(1.27)\end{array}$ \\
\hline $\mathrm{S}-=/ \mathrm{P}-\#$ & $\begin{array}{c}2.14 \\
(0.92)\end{array}$ & $\begin{array}{c}1.29 \\
(1.20)\end{array}$ & $\begin{array}{c}1.90 \\
(0.94)\end{array}$ & $\begin{array}{c}1.27 \\
(1.10)\end{array}$ \\
\hline $\mathrm{S}-\mathrm{S} / \mathrm{P}=$ & $\begin{array}{c}3.21 \\
(0.80)\end{array}$ & $\begin{array}{c}2.36 \\
(0.75)\end{array}$ & $\begin{array}{c}3.27 \\
(1.34)\end{array}$ & $\begin{array}{c}2.00 \\
(1.34)\end{array}$ \\
\hline $\mathrm{S}-\$ / \mathrm{P}-\$$ & $\begin{array}{c}2.57 \\
(0.75)\end{array}$ & $\begin{array}{c}2.43 \\
(0.97)\end{array}$ & $\begin{array}{c}3.36 \\
(0.92)\end{array}$ & $\begin{array}{c}1.55 \\
(1.30)\end{array}$ \\
\hline
\end{tabular}

Note-The higher the mean, the greater the amount of cooperative behavior. Standard deviations are enclosed in parentheses.

significantly more cooperative than the S-\#/P-\# group. There was also a significant main effect of partner's strategy $\quad(F=8.32, \quad p<.01$, $\mathrm{d} f=1 / 104) ; \quad$ Ss with cooperative partners were more cooperative than Ss with competitive partners.

Experiment 2

A chi-square analysis showed the four incentive groups to be significantly different on Trial 1 $\left(x^{2}=23.8, \quad \mathrm{p}<.001, \quad \mathrm{df}=3\right)$, the order of groups being the same as that on Trials 2-5 in Experiment 1 (S-\$/P-\# most cooperative, $\mathrm{S}-\# / \mathrm{P}-\#$ least cooperative). The analysis of variance of Trials 2-5 combined showed the same main effects as for Experiment 1 (incentive: $F=3.22, \quad p<.025$, d $\mathbf{f}=3 / 80 ;$ partner's strategy: $\mathrm{F}=12.17, \mathrm{p}<.01, \mathrm{df}=1 / 80)$ as well as a significant Incentive Group by Partner Strategy interaction $(F=2.86$, $\mathrm{p}<.05, \mathrm{df}=3 / 80$ ). With regard to the incentive main effect, a Newman-Keuls test showed that the $\mathrm{S}$-\#/P-\# group was significantly less cooperative than either of the two S- $\$$ groups but not the S-\#/P-\$ group. With regard to the interaction, a Newman-Keuls test showed that the difference between Ss with cooperative and Ss with competitive partners was significant only for the two S-S groups. (Significance for the Newman-Keuls test was considered to be .05 or better.)

\section{DISCUSSION}

The results obtained were not a clear confirmation of either of the two hypotheses; moreover, interesting differences appeared between the two population samples.

The variable of incentive group (Trials 2-5) had an effect in both of the experiments. The significant difference between the S-\$/P. $\$$ and the $\mathrm{S}-\# / \mathrm{P}-\#$ groups in both of the experiments replicates the Gallo (1966) and McClintock \& McNeel (1966) studies with these two new and different populations. However, in the first experiment only, in the two groups in which the Ss were playing for points, there was significantly more cooperation if the partners were playing for money than if the partners were playing for points. This appears to indicate greater social responsibility in the first population sample, since the Ss' reward was an imaginary one and the presence or absence of a real reward for the partner produced differential action.

In both of the experiments, a main effect of partner's strategy appeared, indicating that both groups reciprocated the cooperation and competition of the other person (perhaps because of the relatively large reward for mutual cooperation). However, a Partner's Strategy by Incentive interaction appeared in the second experiment only, indicating that these $S s$ tended to reciprocate (i.e., match the partner's strategy) more when they themselves were playing for money than when they were playing for points.

It seems likely that the discrepancies between the two experiments can be explained by the socioeconomic levels of the two sample populations. Both experiments were carried out in Grade 9 classes in suburban Toronto high schools. However, post hoc investigation revealed that the school of Experiment 1 is located largely in a government-subsidized public housing project, with many low-income residents, while the school of Experiment 2 is located in a new, modern, possibly upper-middle-class neighborhood, occupied largely by professionals and small business owners. Simmel (1950) has suggested that experience with the exchange of goods and services (as, for instance, in the entrepreneurial class) leads to an economic-exchange view of life. The population of Experiment 2 might conceivably have had greater contact with such a view of life, and thus they showed reciprocity only when a monetary reward was at stake for them and a disregard for social responsibility when they were playing' for points.

It would appear that both the social responsibility notion and socioeconomic variables are fruitful areas for further research with the prisoner's dilemma game.

\section{REFERENCES}

BERKOWITZ, L., \& DANIELS, L. R Responsibility and dependency. Journal of Abnormal \& Social Psychology, 1963. 66, 429-436.

DEUTSCH, M., \& KRAUSS, R. M. The effect of threat upon interpersonal bargaining. Journal of Abnormal \& Social Psychology, 1960,61, 181-189.

GALLO, P. S. Effects of increased incentives upon the use of threat in bargaining. Journal of Personality \& Social Psychology, 1966, 4, 14-20.

GOULDNER, A. W. The norm of reciprocity: A preliminary statement. American Sociological Review, 1960,25 161-179.

MCCLINTOCK, C. G., \& McNEEL, S. P. Reward and score feedback as determinants of cooperative and competitive game behavior. Journal of Personality \& Social Psychology, 1966, 4, 606-613.

SIMMEL, G. The sociology of Georg Simmel. Glencoe, Ill: Free Press, 1950. 